\title{
Quality of primary health care: an analysis of avoidable hospitalizations in a Minas Gerais county, Brazil
}

Carolina Costa Valcanti Avelino ${ }^{1}$

Sueli Leiko Takamatsu Goyatá ${ }^{1}$

Denismar Alves Nogueira ${ }^{2}$

Ludmila Barbosa Bandeira Rodrigues ${ }^{3}$

Sarah Maria Souza Siqueira ${ }^{1}$

${ }^{1}$ Escola de Enfermagem, Universidade Federal de Alfenas. R. Gabriel Monteiro da Silva 700, Centro. 37130000 Alfenas MG Brasil. ccv89@yahoo.com.br ${ }^{2}$ Instituto de Ciências Exatas, Universidade Federal de Alfenas.

${ }^{3}$ Universidade Federal de

Mato Grosso.

\begin{abstract}
The aim of the study was to evaluate the quality of primary health care based on avoidable hospitalizations of men and women of all ages, from 2008 to 2012 in Alfenas County in the south of Minas Gerais state. This was an ecological study based on data from the Hospital Information System (HIS). The medical diagnoses selected for the study were pneumonia, diabetes mellitus and diseases of the circulatory system. There was a predominance of elderly males diagnosed with pneumonia, with an average hospital stay of five days. Admission rates for diseases of the circulatory system and diabetes mellitus tended to remain stable during the study period. While for pneumonia there was a tendency of growth that reached a plateau in early March 2009, bringing the average rate up from 2.01 to 3.51. The data suggest that primary health care is poorly organized to meet these diagnoses, particularly for pneumonia.

Key words Health care quality, Primary health care, Hospitalization
\end{abstract}




\section{Introduction}

Primary Health Care (PHC) is based on characteristics such as first contact, longitudinality/ continuity of care, completeness, coordination, family focus and community guidelines, and includes activities to promote health and disease prevention, through a range of interventions and care. Accordingly, PHC should play an important role as a central communicator of the health care network, which coordinates the flow and counter-flow of the health care system ${ }^{1}$. PHC opens up the possibility to reorganize the requirements and management of the system as a whole and to make changes in the hospital-centered care model. Primary health care is linked to avoidable hospitalizations of specific diseases and these hospitalizations could be prevented with the appropriate action at the appropriate time ${ }^{2}$.

The Family Health Strategy (FHS), which is part of the PHC, aims to meet the needs of a specific community, by adjusting the factors that influence health and disease and consequently improve the overall health indicators ${ }^{3}$. These indicators are used in practice to show the health status of an individual or the population itself when required with reliability and practicality ${ }^{4}$. Hospitalizations for conditions considered preventable have been used as an indirect indicator of the effectiveness of primary health care ${ }^{2,5}$.

Ambulatory Care-Sensitive Conditions (ACSC), also known as potentially avoidable hospitalizations, represent a set of health problems typically solved at the first level of health care, primary care, but without effective and timely assistance, may result in hospitalization ${ }^{5,6}$. ACSC are based on diagnoses recorded in hospitals, which may coincide with the diagnoses made by the ambulatory care doctors ${ }^{7}$. In Brazil, the list of conditions that make up this indicator includes 19 causes of hospitalizations and diagnoses, according to the tenth revision of the International Classification of Diseases and Causes of Death (ICD-10) ${ }^{8}$. In Minas Gerais state, this list was based on Resolution SES/MG No. 1093 of 29 December 2006 .

Hospitalizations for ACSC are an indicator used to evaluate the performance of different health services, the effects of health policies and as part of the resolubility, quality and accessibility evaluations of PHC. Such admissions refer to the care provided during primary care that when effective and agile, can help to reduce the risks of hospitalizations, prevent the onset of an illness, treat an acute illness or manage a chronic disease within the $\mathrm{PHC}^{5,6}$.
High rates of hospitalization for such conditions in a population may be the result of a lack of timely and effective attention to health problems, difficult access to health services, low entailment in primary care services, spontaneous search for specialized services or emergency, which is characteristic of the individual seeking health services or even the low resolubility and effectiveness of the health services in general. An increase in the number of hospitalizations is a warning signal that should initiate analytical mechanisms to explain their occurrance ${ }^{6,10}$.

Studies in Brazil have shown a reduction of hospitalizations due to preventable diseases in various counties in the states of Minas Gerais, Paraná and Ceará, and these have been used as strategies to monitor FHS performance. These investigations are in their infancy and there are some limitations to interpreting the trends of such hospitalizations, such as use of different lists for preventable diseases, making it difficult to compare results. Also there is a lack of information to examine the trends of these avoidable hospitalizations in relation to other causes of hospitalizations ${ }^{6}$.

There is evidence that patients treated in services that follow the PHC principles are hospitalized less by ACSC when compared to those treated in traditional outpatient care services, and polyclinics, among others ${ }^{11}$.

Thus, this study aimed to evaluate the quality of the primary health care service, through a trend analysis of some diseases classified as avoidable hospitalizations in two hospitals in Alfenas County in the south of Minas Gerais state, from 2008 to 2012. It is hoped that this research can stimulate public policies that contribute to the control of hospitalizations for ambulatory care-sensitive conditions, by strengthening the PHC.

\section{Methods}

This study has an ecological, retrospective, descriptive character, with a methodological quantitative approach ${ }^{12}$.

For this study we used the list of conditions that make up the Ambulatory Care-Sensitive Conditions (ACSC) indicator that was established in the Resolution SES/MG No. 1093, of December 29, 2006, for the state of Minas Gerais9. Hospitalization rates for ACSC were calculated by the formula: (number of hospitalizations for ACSC in a given place and period/population in the 
same place and period $x 10,000)$. The data for the study were collected from the records of the Hospital Information System HIS of SUS (Brazilian National Health Service) of the Alfenas County Health Department. In the Alfenas County there are only two hospitals accredited by SUS.

The preventable diseases that cause hospitalizations that were studied here were pneumonia, diabetes mellitus and diseases of the circulatory system (acute rheumatic fever, essential hypertension, hypertensive heart disease, angina pectoris and heart failure). These diseases were selected based on those that presented the most hospitalizations and in agreement with the diseases used by similar studies found in the literatura ${ }^{13-15}$.

The variables that appear on the Hospital Admissions form were studied, namely: sex, age, ICD-10 (tenth revision of the International Classification of Diseases and Causes of Death), admission date, length of stay, category, health facility, type of primary care (urgent/elective), hospitalization costs, date and reason for discharge. Variables such as the number of readmissions, the frequency of hospitalization for the same diagnosis, the number and origin of hospitalized individuals were obtained by the exclusion of repeated Hospital Admissions. It was possible to carry out these procedures as the database of the HIS of Alfenas County was assessable.

The program "Statistical Package for Social Sciences" (SPSS) version 17.0 was used for data analysis. The chi-square test and Spearman's correlation coefficient, with a 5\% significance level, were used for the statistical analysis of the study variables. The time series of hospitalization rates for ambulatory care-sensitive conditions (ACSC) for the years 2008-2012 were used for the medical diagnoses of bacterial pneumonia, diabetes mellitus and diseases of the circulatory system, at monthly intervals. The best model was considered to be the one that gave the highest statistical significance (lowest p-value). A significant trend was considered when $\mathrm{P}<0.05$.

The study was approved by the Ethics Committee of the Federal University of Alfenas.

\section{Results}

In 2008, the area covered by the Family Health Strategy, of Alfenas County, corresponded to $53.42 \%$ (11 teams); in 2009 , to $55.57 \%$ (12 teams); in 2010, to $59.63 \%$ (12 teams). In 2011 this coverage was $60.79 \%$ (13 teams) and, in 2012, decreased to $60.37 \%$ (13 teams $)^{16}$.
In the period investigated (2008-12), 2,200 hospitalizations were recorded as preventable conditions in the two hospitals, accredited to SUS, in the county understudy; there were 1,327 $(60.3 \%)$ for pneumonia, 615 (28\%) for diseases of the circulatory system, and 258 (11.7\%) for diabetes mellitus. The number of readmissions for patients during the four years was 310 (18\%) and $67 \%$ of these were for the same diagnosis as the first hospitalization. Moreover, on excluding readmissions, the number of individuals hospitalized for preventable conditions in Alfenas County was 1,715 . The average hospital stay was 5 days (maximum 101 days). Table 1 shows the sociodemographic characteristics of the patients hospitalized as a result of the diseases under consideration as well as the variables understudy.

The patients included in the study were predominantly male $(54.7 \%)$, the majority of the hospitalizations $(50.5 \%)$ were individuals over 60 years old, and the average age of patients was 51 years old ( $\mathrm{SD}=29.45$ years $) ; 81.9 \%$ were hospitalized due to a clinical diagnosis; $70.5 \%$ were hospitalized in Hospital A and 99.9\% of hospitalizations were considered as an emergency. The preventable disease with the highest number of admissions (60.3\%) was pneumonia and $87.8 \%$ of the discharges were due to clinical improvements (Table 1).

An average of $\mathrm{R} \$ 962.00$ (maximum: R\$ $28,826.90)$ was spent per patient for the hospitalizations during the study period (2008-12), reaching a total cost of $\mathrm{R} \$ 1,695,485.73$ in the period. The average age of patients hospitalized for pneumonia was 42 years old and the amount paid for these hospitalizations was around $\mathrm{R} \$$ 622.00 (max: R\$28,826.90) per patient, reaching a total of $\mathrm{R} \$ 1,075,568.31$ in the four years. However it should be noted that from 2008 to 2009 , there was a significant increase in hospitalization costs for pneumonia. The average age for hospitalizations due to diseases of the circulatory system was 67 years old and the amount paid for the hospitalizations was around R\$949.00 (maximum: R\$ 16,236.00) per patient, making a total of R\$498,195.40 in four years. The average age of patients hospitalized due to diabetes was 53 years old, and the amount paid for these hospitalizations averaged R\$ 521.00 (maximum $\mathrm{R} \$ 9,469.00)$ per patient, making a total of $\mathrm{R} \$$ $121,722.02$ in the period (Table 2).

According to the Spearman correlation coefficient, there was a significant correlation between the variables: value (deflated) paid for hospitalizations and the pneumonia hospitalization 
Table 1. Hospitalizations due to pneumonia, diseases of the circulatory system and diabetes mellitus, according to variables. Alfenas, Minas Gerais, Brazil, 2008-2012.

\begin{tabular}{lrr}
\hline \multicolumn{1}{c}{ Variables } & $\boldsymbol{f}$ & \multicolumn{1}{c}{$\%$} \\
\hline Sex & & \\
Male & 1204 & 54.7 \\
Female & 996 & 45.3 \\
Age group & & \\
Less that 1 year old & 135 & 6.1 \\
1 to 9 years old & 274 & 12.5 \\
10 to 19 years old & 59 & 2.7 \\
20 to 59 years old & 620 & 28.2 \\
Over 60 years old & 1112 & 50.5 \\
Category & & \\
Clinical & 1802 & 81.9 \\
Pediatric & 378 & 17.2 \\
Surgical & 20 & 0.9 \\
Health facility & & \\
Hospital A & 1551 & 70.5 \\
Hospital B & 649 & 29.5 \\
Type of service & & \\
Emergency & 2197 & 99.9 \\
Elective & 3 & 0.1 \\
CID-10 & & \\
Pneumonia & 1327 & 60.3 \\
Diseases of the circulatory system & 615 & 28 \\
Diabetes & 258 & 11.7 \\
Reasons for discharge & & \\
Clinical improvement & 1931 & 87.8 \\
Death & & 9.6 \\
Stay & & \\
Transfer & & \\
& & \\
\hline
\end{tabular}

"Stay may be due to: complications, characteristics of the disease, change of procedure or reoperation. Source: Hospital Admissions. Alfenas 2012. rate $(\mathrm{r}=0.898 ; \mathrm{P}<0.001)$ and diseases of the circulatory system $(r=0.750 ; \mathrm{P}<0.001)$ from 2008 to 2012, which shows an increase in costs for such hospitalizations during the years studied.

According to the chi-square test, these preventable diseases were significantly associated with gender $(\mathrm{P}<0.001)$. There were a greater number of women hospitalized for diabetes than men and a greater number of men hospitalized for diseases of the circulatory system than women. These preventable diseases were also statistically associated with age $(\mathrm{P}<0.001)$, showing a higher number of hospitalizations due to diabetes for the age bracket 10-19 years old than for diseases of the circulatory system. This later disease was dominant in the age group of 60 years old or more. These diseases were also statistically associated with the reasons for discharge ( $\mathrm{p}=$ 0.004 ), revealing that there were fewer deaths in hospitalizations for diabetes than for the other diseases; while diseases of the circulatory system counted for more deaths than had been expected.

On the analyzing the trends in hospitalization rates for preventable diseases during the years 2008-2012, the results showed no significant difference for diseases of the circulatory system and diabetes mellitus, which both remained stable during the study period (Table 3 ). However, for pneumonia, the results showed a significant trend, maintaining a steady growth through the years, and hospitalization rates increased on a monthly basis of 0.04 (Regression Coefficient). A plateau was reached in early March 2009, raising the average rate of 2.01 to 3.51 (Table 3, Figure 1).

Table 2. Admission rates (per 10,000 inhabitants) in SUS (Brazilian National Health System) for preventable diseases and the deflated costs of hospitalizations spent a year in Alfenas, Minas Gerais, Brazil, 2008-2012.

\begin{tabular}{|c|c|c|c|c|c|c|}
\hline \multirow{2}{*}{ Diagnosis } & \multicolumn{5}{|c|}{ Year of admission } & \multirow{2}{*}{ Total } \\
\hline & 2008 & 2009 & 2010 & 2011 & 2012 & \\
\hline Pneumonia & 37.11 & 61.87 & 68.86 & 59.49 & 45.38 & 272.71 \\
\hline Hospitalization Costs (Brazilian reals) ${ }^{*}$ & $72,771.55$ & $192,458.67$ & $343,882.21$ & $198,852.13$ & $267,603.76$ & $1,075,568.31$ \\
\hline Diseases of the circulatory system & 15.37 & 16.87 & 14.10 & 19.34 & 17.69 & 83.37 \\
\hline Hospitalization Costs (Brazilian reals) & $78,220.94$ & $106,812.84$ & $100,695.01$ & $102,813.44$ & $109,653.17$ & $498,195.40$ \\
\hline Diabetes mellitus & 7.34 & 7.82 & 6.51 & 5.91 & 7.45 & 35.03 \\
\hline Hospitalization Costs (Brazilian reals) ${ }^{*}$ & $21,462.97$ & $22,200.44$ & $35,937.58$ & $17,939.10$ & $24,181.92$ & $121,722.02$ \\
\hline
\end{tabular}

Deflated costs for 2008 according to the National Consumer Price Index (IPCA). Source: Hospital Admissions. Alfenas, 2012. 
Table 3. Analysis of the trend of hospitalization rates for preventable diseases over the period studied in Alfenas, Minas Gerais, Brazil, 2008-2012.

\begin{tabular}{lcccc}
\hline \multicolumn{1}{c}{ Diagnosis } & Average & $\mathbf{R}$ & $\mathbf{p}$ & Tendency \\
\hline Pneumonia & Level 1: 2.01 & 0.51 & $<0,001$ & Growth \\
& Level 2:3.51 & & & \\
Diseases of the Circulatory System & 1.38 & 0.08 & 0,18 & Not significant \\
Diabetes Mellitus & 0.58 & 0.00 & 0,51 & Not significant
\end{tabular}

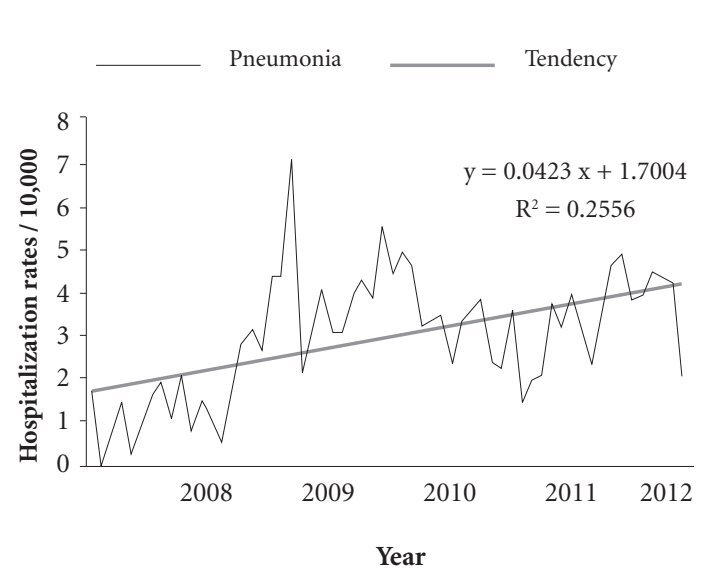

Figure 1. Hospitalization rates for pneumonia (per 10,000 inhabitants) in Alfenas, Minas Gerais, Brazil, 2008-2012.

The hospitalization rates for pneumonia for all age brackets remained stable over the four years except for the 60 years old and over bracket which had monthly growth $(\mathrm{P}<0.001)$ rates of 0.0265 (Regression Coefficient). This latter age bracket also showed a plateau of hospitalizations in early March 2009 (Figure 2).

\section{Discussion}

Since 1998, Brazil has been progressively expanding the Family Health System (FHS), growing from a presence in 1,134 to 5,297 counties through to 2012, and with a current population-coverage of approximately $55 \%$. In the state of Minas Gerais this growth has been even more significant, and currently has a population-coverage of $71 \%{ }^{16}$. In Alfenas County, where the study was conducted, the growth rate has been similar to that of the state and has a current popula- tion-coverage of $60 \%$. This growth occurred faster in counties with smaller populations, due to the financial incentives for these low population-coverage ranges of $\mathrm{FHS}^{2}$. However, this expansion by counties in Brazil presents some discrepancies, not only in population-coverage, but also in the ways of operating and in the organization of the health services, which should be considered when comparing hospitalization rates for ACSC, as an assessment indicator of primary care ${ }^{2}$.

The results presented in this study showed that the ACSC hospitalization rates, for the diseases understudy, remained stable during the study period, except for pneumonia, which grew. This result differs from surveys conducted in several other regions in Brazil, such as in Rio Grande do Sul, Goiás, Minas Gerais and Piauí that have shown a significant decrease in preventable diseases over the years ${ }^{15,17-19}$. As we consider the care cover percentage of the FHS as an indicator that can have an impact on reducing avoidable hospitalizations, this may be associated with the year this study started, which retrospectively gathered data in the period prior to 2008, a period in which there was a significant increase in the Family Health teams, different from the years between 2008 to 2012 in which the FHS population coverage in the Brazil grew by only $7.52 \%$, and during this latter period only one new FHS team was instigated in the county under study ${ }^{16}$.

Considering the growing trend of hospitalizations for pneumonia, mainly in the elderly, a study by Fernandes et al. ${ }^{11}$ refers to pneumonia as one of the major causes of avoidable hospitalizations and claims that the elderly, in general, are the ones most affected by this disease. The study by Moura et al. ${ }^{20}$ showed a decrease in pneumonia between the years 1999 and 2006, however this disease was also considered a major cause of hospitalizations.

Rehem and Egry ${ }^{21}$ reviewed the Ambulatory Care-Sensitive Conditions (ACSC) in São Paulo 


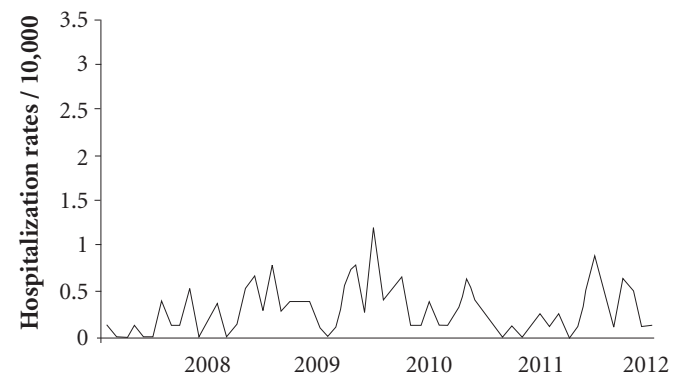

(a)

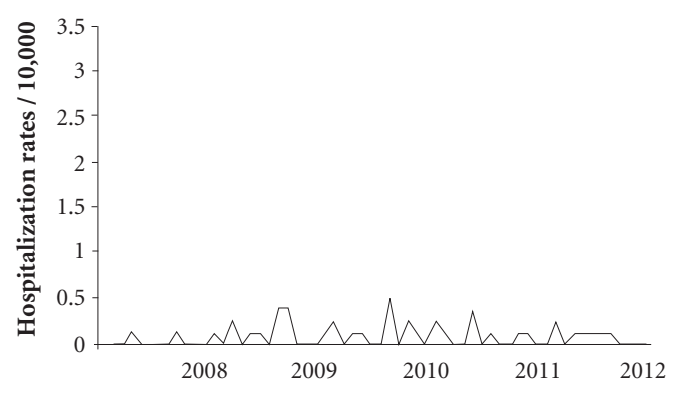

(c)

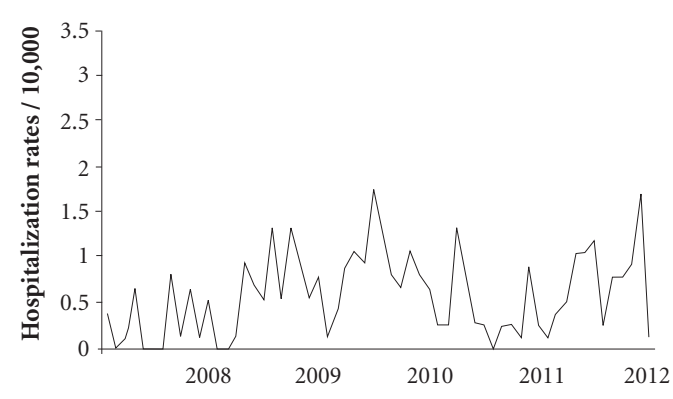

(b)

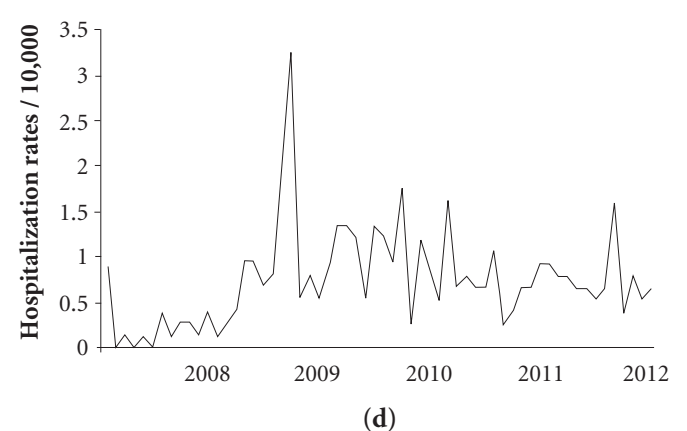

(d)

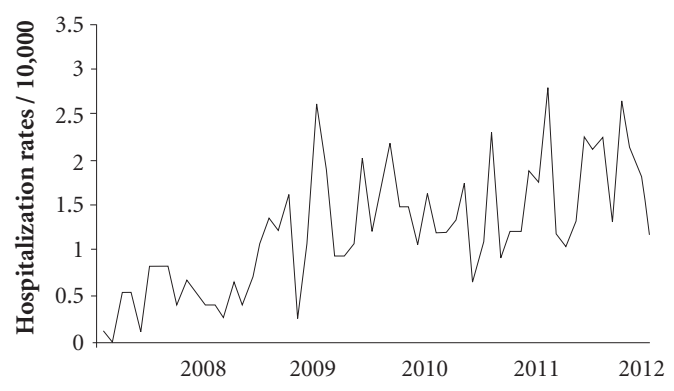

(e)

Figure 2. Hospitalization rates for pneumonia (per 10,000 inhabitants) in terms of the age brackets (a) $<1$ year old, (b) 1-9 years old (c) 10 to 19 years old, (d) 20 to 59 years old and (e) 60 years old or more, in Alfenas, Minas Gerais, Brazil, 2008-2012.

and found increased rates of hospitalization for bacterial pneumonia, skin and subcutaneous infections in ten counties of that state. These data indicate that primary care is poorly organized to meet these diagnoses, especially for pneumonia.

Considering the FHS care coverage in the county under study, the average monthly hospitalizations for pneumonia in the elderly were expected to decrease and not to increase to the extent that was observed in this study ${ }^{20}$. Elias and Magajewski ${ }^{14}$ claim that there is a strong relationship between the appropriate actions of the FHS and the decline of hospitalizations for pneumonia in the elderly, since even with the few technological resources available for PHC they are sufficient for early diagnosis and treatment of this pathology, and are therefore able to prevent unnecessary hospitalizations.

The study by Fernandes et al. ${ }^{11}$ reported that there was a predominance of hospitalizations 
due to diseases of the circulatory system in elderly male individuals and the average length of stay was 5 days. This study also confirmed that the leading causes of these hospitalizations were heart failure and coronary heart disease in elderly males. According to the Ministry of Health ${ }^{22}$ "Many illnesses could be prevented if men carried out, regularly, the primary prevention measures. The male resistance to primary health care not only increases the financial burden of society, but also, and above all the physical and emotional suffering of the patient and his family in the struggle for preservation of health and quality of life of these people".

The results found for diabetes in this work are in line with the results described by Moraes et al. $^{23}$, who assessed the prevalence of diabetes in Ribeirão Preto, and also reported a greater number of women affected by this disease.

There was an increase in the costs for pneumonia, diseases of the circulatory system and diabetes, during the years studied. The total amount paid for these avoidable hospitalizations could be used as a saving strategy for the health system, because if this cost was directed to primary care it could increase the effectiveness of such care ${ }^{13}$.

Studies that use data from the HIS of SUS have some limitations such as: the system only records the hospitalizations in the SUS system, which represents about $70 \%$ of hospitalizations in Brazil ${ }^{2}$. Hospitalizations for ambulatory care-sensitive conditions also occur in private hospitals ${ }^{8}$. In addition, a double or triple count of the same patient can occur, because the system does not identify readmissions and transfers from other hospitals; and there is no possibility of subsequent corrections to the invoiced revenue, even if a typo or diagnostic code error is identified $^{2}$.

However, some of these limitations were anticipated in this study, as the data were gathered from the records of the county HIS, which allowed access to the database itself with the information of Hospitalizations that included readmissions, the frequency of hospitalization for the same diagnosis and thus it was possible to obtain the correct number of hospitalized individuals.
Furthermore, during a review of the literature for this study, we found no studies that used an institutional database at the municipal level to search and analyze results at this level of detail.

\section{Final considerations}

There was a predominance of elderly males diagnosed with pneumonia and this type of hospitalization had a significant impact on costs. As pneumonia is an acute respiratory infection and there are technological and therapeutical resources available in primary care, this cost increase shows that there is little appropriate action at this level of care.

The results of this study of preventable diseases showed that $18 \%$ of the individuals were readmitted and of these, $67 \%$ were hospitalized for the same disease. The implementation of a Hospital Admissions Information System within the county administration, in the Regulation, Control and Evaluation Sector, provides important information, such as readmissions, the frequency of hospitalization for the same diagnosis, the number of individuals and also provides information of where the individuals admitted to different hospitals came from. A county system of registration of admissions contributes substantially to the process of avoidable hospitalization analyses. The use of such variables for this type of research is important for the indirect evaluation of the quality and solvability of care provided by primary health care units under the Brazilian National Health System, both for health professionals and the health administrators.

The short period of five years of this study may be a limitation. Thus, time series analyses of studies with longer search periods are recommended.

The use of Ambulatory Care-Sensitive Conditions (ACSC) hospitalizations as an indicator can be a valuable tool for monitoring and assessing the quality, performance and access to primary health care $(\mathrm{PCH})$, which is the central coordinator for the health care networks within the Brazilian National Health System. 


\section{Collaborators}

CCV Avelino, SLT Goyatá, DA Nogueira, LBB Rodrigues and SMS Siqueira participated equally in all the preparation stages of this article. 


\section{References}

1. Mendes EV. As redes de atenção à saúde. Cien Saude Colet 2010; 15(5):2297-2305.

2. Campos AZ, Theme-Filha MM. Internações por condições sensíveis à atenção primária em Campo Grande, Mato Grosso do Sul, Brasil, 2000 a 2009. Cad Saude Publica 2012; 28(5):845-855.

3. Brasil. Ministério da Saúde (MS). Manual técnico para estruturação física de unidades de saúde da família. Editora MS 2006. [Página da Internet] [acessado 2014 jan 15]. Disponível em: http://dtr2004.saude.gov.br/somasus/Dinamicos/Documentos.htm.

4. Pires VATN. Internações hospitalares por condições sensíveis à atenção ambulatorial: um estudo de caso com gestores e equipes da Estratégia Saúde da Família em uma microrregião de saúde [dissertação]. Belo Horizonte: Universidade Federal de Minas Gerais; 2008.

5. Nedel FB, Facchini LA, Martín M, Navarro A. Características da atenção básica associadas ao risco de internar por condições sensíveis à atenção primária: revisão sistemática da literatura. Epidemiol Serv Saúde 2010; 19(1):61-75.

6. Alfradique ME, Bonolo PF, Dourado I, Lima-Costa MF, Macinko J, Mendonça CS, Oliveira VB, Sampaio LFR, Simoni C, Turci MA. Internações por condições sensíveis à atenção primária: a construção da lista brasileira como ferramenta para medir o desempenho do sistema de saúde (Projeto ICSAP - Brasil). Cad Saude Publica 2009; 25(6):1337-1349.

7. Gérvas J, Caminal JH. Las hospitalizaciones por ambulatory care sensitive conditions (acsc) desde el punto de vista del médico de atención primaria. Rev Esp Salud Pública 2007; 81(1):7-13.

8. Cardoso CS, Pádua CM, Rodrigues-Júnior AA, Guimarães DA, Carvalho SF, Valentin RF, Abrantes R, Oliveira CDL. Contribuição das internações por condições sensíveis à atenção primária no perfil das admissões pelo sistema público de saúde. Rev Panam Salud Publica 2013; 34(4):227-234.

9. Minas Gerais. Secretaria de Estado de Saúde. Resolução SES/MG nº. 1093, de 29 de dezembro de 2006. Estabelece condições que compõem o indicador Internações Sensíveis à Atenção Ambulatorial. Diário Oficial de Minas Gerais 2006; 29 dez.

10. Dias-da-Costa JS, Büttenbender DC, Hoefel AL, Souza LL. Hospitalizações por condições sensíveis à atenção primária nos municípios em gestão plena do sistema no Estado do Rio Grande do Sul, Brasil. Cad Saude Publica 2010; 26(2):358-364.

11. Fernandes VBL, Caldeira AP, Faria AA, Neto JFR. Internações sensíveis na atenção primária como indicador de avaliação da Estratégia Saúde da Família. Rev Saude Publica 2009; 43(6):928-936.

12. Pereira MG. Epidemiologia teoria e prática. Rio de Janeiro: Guanabara Koogan; 2008.
13. Dias-da-Costa JS, Borba LG, Pinho MN, Chatkin M. Qualidade da atenção básica mediante internações evitáveis no Sul do Brasil. Cad Saude Publica 2008; 24(7):1699-1707.

14. Elias E, Magajewski F. A Atenção Primária à Saúde no sul de Santa Catarina: uma análise das internações por condições sensíveis à atenção ambulatorial, no período de 1999 a 2004. Rev Bras Epidemiol 2008; 11(4):633647.

15. Batista SRR, Jardim PCBV, Sousa ALL, Salgado CM. Hospitalizações por condições cardiovasculares sensíveis à atenção primária em municípios goianos. Rev Saude Publica 2012; 46(1):34-42.

16. Brasil. Ministério da Saúde (MS). Departamento de Atenção Básica (DAB). Histórico de Cobertura da Saúde da Família. Brasília: MS. [Página da Internet] [acessado 2013 dez 20]. Disponível em: http://dab.saude.gov.br/ portaldab/historico_cobertura_sf.php

17. Souza LL, Costa JSD. Internações por condições sensíveis à atenção primária nas coordenadorias de saúde no RS. Rev Saude Publica 2011; 45(4):765-772.

18. Rodrigues-Bastos RM, Campos SEM, Ribeiro LC, Firmino RUR, Bustamante-Teixeira MT. Internações por condições sensíveis à atenção primária em município do sudeste do Brasil. Rev Assoc Med Bras 2013; 59(2):120-127.

19. Barreto JOM, Nery IS, Costa MSC. Estratégia Saúde da Família e internações hospitalares em menores de 5 anos no Piauí, Brasil. Cad Saude Publica 2012; 28(3):515-526.

20. Moura BLA, Cunha RC, Aquino R, Medina MG, Mota ELA, Macinko J, Dourado I. Principais causas de internação por condições sensíveis à atenção primária no Brasil: uma análise por faixa etária e região. Rev Bras Saúde Matern Infant 2010; 10(Supl. 1):S83-91.

21. Rehem TCMSB, Egry EY. Internações por Condições Sensíveis à Atenção Primária no Estado de São Paulo. Cien Saude Colet 2011; 16(12):4755-4766.

22. Brasil. Ministério da Saúde (MS). Política nacional de atenção integral à saúde do homem (princípios e diretrizes). Brasília: MS; 2008.

23. Moraes AS, Freitas ICM, Gimeno SGA, Mondini L. Prevalência de diabetes mellitus e identificação de fatores associados em adultos residentes em área urbana de Ribeirão Preto, São Paulo, Brasil, 2006: Projeto OBEDIARP. Cad Saude Publica 2010; 26(5):929-941.

Article submitted 03/26/2014

Approved 09/11/2014

Final version submitted 10/03/2014 
